\title{
Analysis on the Emotional Labor Effect of Medical Staff in Chinese Public Tertiary Hospitals
}

\author{
Yichao Luan ${ }^{1, *}$ \\ ${ }^{1}$ University of Illinois at Urbana-Champaign, Champaign, IL IL61820, USA \\ ${ }^{*}$ Corresponding author. Email: caraluan1030@gmail.com
}

\begin{abstract}
Emotional labor in the research field of service industry has been valued by organizations, managers and service employees. As a high-frequency and high-intensity emotional labor group, the two emotional labor strategies adopted by medical staff, surface acting performance and deep acting performance, have an important impact on the medical staff's own mental health, job satisfaction, patient satisfaction and loyalty. Surface acting performance plays a restraining role, while deep acting performance does the opposite. Based on the theory of unconscious emotional infection and the analysis of patients' irrational behavior, this article analyzes the working conditions of medical staff in China's public tertiary hospitals and the important role of emotional labor.
\end{abstract}

Keywords: Emotional labor, Medical staff, Surface acting performance, Deep acting performance, Doctor-patient relationship.

\section{INTRODUCTION}

In today's prevailing service economy, patients have always been the leading judge of service quality. However, the leading factors that affect the patient experience are not limited to the hospital's environment, scale or level of equipment, and doctors' skills. Emotional labor of medical staff also plays a vital role as mental and physical labor. Especially in the year when the COVID-19 is raging around the world, the importance of public health services has been highlighted. The level of human medical care, science and technology is being challenged, and medical staff and patients around the world are also under unprecedented pressure and tests. At this tense moment, medical staff undertake the important task of stabilizing their own emotions and comforting patients' emotions.

This article will introduce the concept of emotional labor and explain its development and importance to the field of medical services. At the same time, it briefly analyzes the characteristics of the working environment, the problems and threats faced by medical staff in China's public tertiary hospitals, and gives countermeasures.

\section{DEFINITION OF EMOTIONAL LABOR}

American sociologist Arlie Russell Hochschild (1983) did the research on the service process of the interaction between airline flight attendants and passengers. It was found that employees not only need to provide mental and physical work, but also need to regulate their internal feelings and external expression in order to complete the work effectively. Hochschild called this form of labor emotional labor, which requires employees to show a certain emotion at work in order to achieve the goal of their position[1].

Hochschild (1983) claimed that early emotional labor is mainly explained in three parts, namely internal mental state, external behavior and internal adjustment process. Ashforth and Humphrey (1993) made a new interpretation of the definition of emotional labor. They weakened the process of employees' emotional experience and believed that emotional labor is the visible behavior that employees make according to the requirements of the organization[2]. However, Grandey (2000) and Brotheridge (2002) paid more attention to the internal process of employees' emotional adjustment to meet organizational requirements. 
Although scholars have different definitions of the concept of emotional management, they admit that its essence is the process of emotional regulation of employees and the expression that ultimately meets organizational requirements[3].

Emotional labor is a relatively new research field, and scholars still have big differences on its definition and testing. This research originated in the West, and nowadays, as global service organizations, they attach importance to the quality of employee service, employee mental health, customer experience, and the smooth development of organizational management. Emotional labor, as a cross-topic of psychology, sociology and organizational behavior, has attracted attention from all walks of life.

Grandy (2000) and Glomb (2004) analyzed emotional labor from the internal psychological process and external behavior of employees respectively[4]. Grandy proposed that when employees' internal and external feelings are inconsistent, they will use surface acting performance and deep acting performance to achieve the expected service effect of the organization. However, Glomb believes that employees need to experience three different dimensions of emotional expression, that is, disguised emotional expression, suppressed emotional expression and true emotional expression. The performance strategies and emotional expression dimensions proposed by the two scholars require employees to put in their efforts while taking part of the work pressure.

\section{THE IMPORTANCE OF EMOTIONAL LABOR OF MEDICAL STAFF}

With the increase in the proportion of the service industry in recent years, as one of the groups, medical staff need to spend a lot of emotional labor in their daily work. Paying attention to their emotional changes, analyzing their internal and external performance, and properly guiding their behaviors will not only benefit their physical and mental health, but also help improve their work performance and enhance their organizational cognition, thereby gaining patient recognition and establishing a friendly doctorpatient relationship.

\subsection{Improvement of Work Efficiency and Organizational Identity}

The results of the early emotional labor theory show that the impact of emotional labor on employees is mostly negative. This theory believes that frequent surface performance strategies will exhaust employees' emotions, weaken their sense of self-identity, and endanger their mental health. This will directly have a negative impact on employees' work enthusiasm and performance.

However, research in recent years has shown that employees change their self-perception when adopting deep performances, weaken the conflict with customers, and bring positive psychological experience. In addition, emotional labor can not only affect employees' own psychological state and attitude toward work, but also significantly affect employees' work efficiency.

\subsection{Improvement of Patient Safety and Establishment of Friendly Doctor- Patient Relationship and Customer Loyalty (Customer Identity Theory)}

According to the theory of unconscious infection, patients are also the recipients of emotions when they are in the hospital. Falkenberg et al. (2008) found when patients receive services from medical staff, they compare their inner emotions with the emotions expressed by medical staff[5]. At the same time, information that whether others are willing to serve themselves can be obtained through the emotional expression of medical staff, so as to determine whether they are willing to receive services. In addition, Pugh (2001) claimed that in the service process, the emotional receiver will subconsciously imitate the emotional expression of the emotional sender, thereby affecting the emotional change of the emotional receiver[6].

\section{WORKING ENVIRONMENT OF MEDICAL STAFF IN CHINESE PUBLIC TERTIARY HOSPITALS}

In this article, we use China's public tertiary hospitals as the research background. The service tenet of public tertiary hospitals is to always adhere to the people-oriented principle and put the interests of patients first. Public tertiary hospitals have obvious advantages in terms of medical equipment, medical conditions, and professionalism of medical staff. At the same time, there is a problem of 
uneven distribution of medical resources in China, and a large number of patients are more inclined to choose public tertiary hospitals with high-quality medical resources. Due to the imperfect triage system in China, a large number of patients have been in a state of registration difficulties and shortage of medical resources after entering the public tertiary hospitals. This can easily lead to irritability and irrational behavior in patients. Medical staff need to face overloaded work pressure. The long-term and high-pressure emotional labor of medical staff in such a busy working environment will reduce their work enthusiasm, and even experience emotional exhaustion or resignation.

\section{PUBLIC TERTIARY HOSPITALS IN CHINA}

Cai Weiping, director of the Department of Infectious Diseases, Guangzhou Eighth People's Hospital, said that in recent years, cases of violent wounding and killing of doctors have often occurred. In the past 10 years, the total number of violent medical incidents has been on the rise. From July 2001 to July 2018, a total of 47 violent medical injuries resulted in the death of medical staff. Guangdong, Jiangsu, Zhejiang and Beijing are high incidence areas. Among them, $67.6 \%$ of violent medical injuries occurred in public tertiary hospitals[7]. And the higher the level of the hospital, the larger the scale of the bad incident. Cai Weiping also added that the departments with high to low incidence of violent injuries are the emergency department, outpatient hall, internal medicine, and ICU. The outpatient and emergency department has always been a department with a high incidence, and the incidence of violent injuries in the emergency department has increased significantly.

Frequent incidents of this kind have made the already fragile doctor-patient relationship tenser. At the same time, the occurrence of a series of malignant incidents has also led to the loss of talents in the Chinese medical field, the decline of the proportion of young Chinese doctors, and the dissolution of anxiety and work enthusiasm of medical staff in the work process.

\subsection{Realistic Problems Faced by Medical Staff in China's Public Tertiary Hospitals}

Scholars such as Yang (2013) emphasized that medical staff need to spend a lot of time communicating and interacting with patients during the work process[8]. In this process, the negative behaviors feedback from patients will affect the emotional labor strategy of medical staff. When patients hold false beliefs or unmatched information, patients are more likely to take irrational behaviors such as verbal insults, emotional out-of-control or physical conflicts.

Professor Yang Yong and other scholars adopted bootstrapping mediation effect method and Wen Zhonglin's test ideas, and concluded that customer irrational behavior significantly affects surface performance, customer irrational behavior significantly affects work pressure and work pressure significantly affects surface performance. According to the "Table 1", work pressure has a positive effect on surface performances and a significant negative effect on deep performances. In this article, the identity of the medical staff is equivalent to the interpersonal interactor, the patient is the customer receiving the service, and the irrational behavior of the customer is also compared to the irrational behavior of the patient. The irrational behavior of patients as a source of stress is that medical staff produce work pressure during contact with patients. In this case, medical staff need to mobilize their own resources to relieve their work pressure, which leads to the reduction of their emotional labor strategies.

Table 1. Test results of intermediary effect of work stress [8]

\begin{tabular}{|c|c|c|c|c|c|c|}
\hline $\begin{array}{l}\text { Working pressure } \\
\text { (b) }\end{array}$ & $\begin{array}{l}\text { Irrational behavior, surface acting } \\
\text { Irrational behavior, } \\
\text { deep acting }\end{array}$ & $\begin{array}{l}0.043^{*} \\
0.024^{*}\end{array}$ & $\begin{array}{l}0.035^{\star *} \\
0 / 035^{\star *}\end{array}$ & $\begin{array}{l}0.038^{*} \\
0.027^{*}\end{array}$ & $\begin{array}{l}0.049^{*} \\
0.042^{*}\end{array}$ & $\begin{array}{l}\text { Valid } \\
\text { Valid }\end{array}$ \\
\hline
\end{tabular}




\subsection{Preventive Solution}

Patient satisfaction and loyalty can be obtained through medical staff's control over emotional labor, which can be divided into surface acting performance and deep acting performance. Medical staff only adjust their external expressions rather than negative inner feelings when they come into contact with patients. This strategy can be called a surface acting performance by medical staff. On the contrary, as a performance strategy that can positively affect customer loyalty intentions, deep acting performance requires medical staff to truly achieve the emotions expected by the organization mobilizing their empathy, sympathy, enthusiasm or good memories. Grandey (2000) proposed that deep acting performance strategies are considered to be sincere signals sent by emotional workers. Yagil (2012) explained that this signal makes the serviced patients subconsciously perceive the strong willingness of medical staff to provide satisfactory services to patients. Therefore, the services of medical staff are recognized, and a positive and friendly doctor-patient relationship has been formed[9].

Hospital administrators can try to build a more secure and supportive workplace environment, and create a situation for medical staff to resolve negative psychology within the hospital. Under normal circumstances, as a front-line medical staff, their work is very intense, and their emotional exhaustion is very serious. It is common to be treated with a bad attitude, and medical staff must even worry about their personal safety. Erickson and Grove (2008) believed that it is beneficial to encourage experienced employees within the organization to share their work experience in order to improve everyone's ability to deal with patients' non-ideal behaviors[10]. In addition, professional emotional management training is also necessary to improve the skills of medical staff in emotional communication. Hospital administrators can make full use of their psychological resources to regularly organize medical staff to talk to each other, empathize, support, or provide psychological counseling. Keeping abreast of the psychological dynamics of hospital employees and giving guidance in time to try to avoid the occurrence of bad events caused by emotional labor have to be taken into consideration. In addition, the sense of fairness inside and outside the organization is also crucial for emotional workers. Fair work procedures, managers and distribution can help suppress the surface acting performance of high- intensity emotional workers, and at the same time stimulate the use of deep acting performance strategies.

\section{CONCLUSION}

Medical organization managers can use the emotional labor strategy of deep performance to positively affect customer loyalty to train and manage medical staff in emotional labor. As a manager of a medical organization, it is necessary to realize that patients' irrational behavior is one of the sources of work pressure for medical staff, and should grasp and relieve the mood of medical staff in time. Chinese medical organization managers began to realize the important role of emotional labor in organizational management lately. They have limited professional knowledge of emotional labor, and there are still many deficiencies in the harmonious construction and atmosphere adjustment of the atmosphere of medical organizations.

\section{AUTHORS' CONTRIBUTIONS}

This paper is independently completed by Yichao Luan.

\section{REFERENCES}

[1] Hochschild, A., 1983. THE MANAGED HEART: COMMERCIALIZATION OF HUMAN FEELING. BERKELEY; LONDON: UNIVERSITY OF CALIFORNIA PRESS, pp.42-65.

[2] Ashforth, B. and Humphrey, R., 1993. Emotional Labor in Service Roles: The Influence of Identity. Academy of Management Review, 18(1), pp.88-115.

[3] Brotheridge, C. and Grandey, A., 2002. Emotional Labor and Burnout: Comparing Two Perspectives of "People Work". Journal of Vocational Behavior, 60(1), pp.17-33.

[4] Glomb, T. and Tews, M., 2004. Emotional labor: A conceptualization and scale development. Journal of Vocational Behavior, 64(1), pp.6-13.

[5] Falkenberg, I., Bartels, M. \& Wild, B. Keep smiling! Eur Arch Psychiatry Clin Neurosc 258, 245-253 (2008). https://doi.org/10.1007/s00406-007-0792-5. 
[6] Pugh, S., 2001. Service with a Smile: Emotional Contagion in the Service Encounter. Academy of Management Journal, 44(5), pp.1018-1027.

[7] Chen, s., Beijing News.26 November 2020. http://www.bjnews.com.cn/news/2020/05/24/7 30871.html.

[8] Yang, Y., Ma, Q., Liu, Z. and Ma, Y., 2013. Effect Mechanism of Customer's Irrational Behavior On Emotional Labor: From Perspective Of Mediated Effect Of Job Stress — Technology Economics. 6 December 2020. http://en.cnki.com.cn/Article_en/CJFDTotalJSJI201303021.htm.

[9] Yagil, D., 2012. The mediating role of engagement and burnout in the relationship between employees' emotion regulation strategies and customer outcomes. European Journal of Work and Organizational Psychology, 21(1), pp.150-168.

[10] Erickson, R. and Grove, W., 2008. Emotional Labor and Health Care. Sociology Compass, 2(2), pp.704-733. 